\title{
(e) Anstrumento
}

ISSN 1984-5499

Licenciado sob uma Licença Creative Commons

\section{Personagem em Libras: o trabalho com textos descritivos na formação do pedagogo}

\author{
Character in Libras (Brazilian Sign Language): the work with descriptive texts in the \\ information of the educator
}

Personaje em Libras: el trabajo con textos descriptivos en la formación del pedagogo

\author{
Adriana Moreira de Souza Corrêa ${ }^{1}$ \\ Professora da Universidade Federal de Campina Grande, Cajazeiras/PB, Brasil \\ Alanna Gadelha Batista ${ }^{2}$ \\ Graduada pela Universidade Federal de Campina Grande, Cajazeiras/PB, Brasil \\ Egle Katarinne Souza da Silva ${ }^{3}$ \\ Gestora da Rede Estadual de Ensino da Paraíba, Cajazeiras/PB, Brasil
}

Recebido em: 15/05/2020

Aceito em: 23/07/2020

10.34019/1984-5499.2020.v22.30624

\section{Resumo}

A formação de professores para as práticas inclusivas e emancipatórias em sala de aula é um desafio para as instituições de ensino superior. Por isso, é relevante socializar as experiências realizadas nesse nível de ensino. Diante disso, objetivamos analisar a apresentação de personagem, uma atividade de produção textual do tipo descritivo, em Língua Brasileira de Sinais (Libras), desenvolvido junto à uma turma de Pedagogia do Centro de Formação de Professores, da Universidade Federal de Campina Grande, campus Cajazeiras - PB, no semestre 2016-2. A metodologia utilizada na pesquisa foi o relato de experiência. Os dados foram analisados em uma abordagem qualitativa. Concluímos que a atividade favoreceu a construção, junto aos licenciandos, de aprendizados que os permitem refletir sobre aspectos lexicais, semânticos e pragmáticos de uso da Libras, bem como na inserção desse sistema linguístico em atividades didáticas que podem ser propostas em classes inclusivas com surdos.

Palavras-chave: Formação de professores. Classe inclusiva. Libras.

\footnotetext{
Abstract

${ }^{1}$ E-mail: adriana.korrea@gmail.com

2 E-mail: alannagadelha2014@gmail.com

${ }^{3}$ E-mail: eglehma@gmail.com
}

The teacher training for emacipating and inclusive practices in classroom has been a challenge for Colleges and universities. Thus, it is impotant to socialise the experiences accomplished in this level of teaching. In this view, we aimed to analyse the presentation of the character, an activity of descriptive textual production in Brazilian Sign Language (Libras), carried out in an Education class of the Teacher Training Center of the Federal University of Campina Grande and Cajazeiras, in Brazil, in the semestre 2016-2. The methodolgy used in the research was the experience report, and data were analysed in a qualitative approach. We concluded that the activity helped the construction of learnings that allowed university students to think on pragmatic, semantic and lexical 
aspects of the use of Libras, as well as in inclusion of this language in didatic activities which can be proposed in inclusive classes with the deaf people.

Keywords: Teacher training. Inclusive class. Libras.

\section{Resumen}

La formación de profesores para las prácticas inclusivas y de emancipación en clases es un desafío para las instituciones de la enseñanza superior. Por lo tanto, es importante analizar y socializar las experiencias hechas en ese nivel de enseñanza. De supuesto, objetivamos analizar la presentación del personaje, una actividad de producción de texto descriptivo, en la Lengua Brasileña de Señales (Libras), desarrollada juntamente con una clase de pedagogía del Centro de Formación de Profesores de la Universidad Federal de las ciudades de Campina Grande y Cajazeiras, en Brasil, en el semestre 2016-2. La metodología empleada en la investigación fue el Informe de Experiencia, y los datos fueron analizados en un abordaje cualitativo. La conclusión es que la actividad ha favorecido la construcción de aprendizajes que permiten a los universitarios reflexionar acerca de los aspectos léxicos, semánticos y pragmáticos del uso de Libras, además de la inclusión de esa lengua en actividades didácticas, las cuales pueden ser propuestas en clases inclusivas con sordos.

Palabras claves: Formación de profesores. Clase inclusiva. Libras.

\section{Introdução}

A formação de professores para o ensino em classes inclusivas é um desafio para as instituições de ensino superior, tendo em vista que esses momentos formativos devem gerar nos licenciandos, percepções e práticas de ensino diferenciadas. Dessa maneira, além de apresentar a organização escolar necessária para a promoção da inclusão, trabalhar as legislações que garantam direitos de inserção de recursos humanos e materiais para favorecer a aprendizagem e ensinar a Língua Brasileira de Sinais (Libras), o docente da Instituição de Ensino Superior (IES) que ministra esse componente curricular deve compreender o seu papel de sensibilizar o licenciando para trabalhar em uma perspectiva inclusiva haja vista que há múltiplas formas do estudante interagir com o mundo e essas estratégias de ensino interferem no seu aprendizado com a finalidade de atender a diversidade humana conforme orienta a Lei de Diretrizes e Bases da Educação (LDB) no 9.394 (BRASIL, 1996).

Entre os estudantes público-alvo da educação inclusiva (BRASIL, 1996) destacamos, neste escrito, o surdo, que se caracteriza como usuário da Libras que interage com o mundo, predominantemente, pela visualidade (BRASIL, 2005). Este estudante, quando inserido em uma classe inclusiva ${ }^{4}$, precisa receber o suporte do Tradutor Intérprete de Libras, profissional que realiza a tradução/intepretação entre o par linguístico Libras e Língua Portuguesa (BRASIL, 2010), nas interações entre surdos e ouvintes.

Contudo, em uma educação que se propõe a ser bilíngue (BRASIL, 2005), a inserção desse profissional não implica que o professor regente deva se eximir do uso da Libras em sala de aula, ao

\footnotetext{
${ }^{4}$ Classe comum da escola regular que oferece os recursos e serviços para o aprendizado dos surdos (BRASIL, 1996).
} 
contrário, esse educador deve promover atividades nas quais essa Língua de Sinais seja reconhecida, utilizada e divulgada por todos os membros da comunidade escolar, em especial os colegas de mesma classe do que o surdo. Isso porque a escola se constitui em um ambiente de socialização e, nesse processo, o compartilhamento de uma língua é fundamental para promover os encontros de ideias e favorecer a interlocução entre os estudantes.

Dessa maneira, buscando refletir sobre atividades em Libras na formação do licenciando, objetivamos analisar uma apresentação de personagem em Libras, uma atividade de produção de texto do tipo descritivo, em Libras, desenvolvido por uma turma de Pedagogia do Centro de Formação de Professores (CFP) - Campus Cajazeiras/PB - da Universidade Federal de Campina Grande (UFCG), no semestre 2016.2. Para isso, realizamos um relato de experiência, produzido de maneira explicativa, com dados analisados em uma perspectiva qualitativa.

A proposta ora apresentada se insere na perspectiva de produção e leitura de textos pautada na multimodalidade, apresentada por Descardeci (2002), na qual aprender a língua não se restringe à internalização do código, mas à compreensão das especificidades do contexto de uso.

\section{Experiências de uso de textos em Libras na formação do Pedagogo}

A Formação de professores para trabalhar em turmas compostas por estudantes usuários da Libras como Primeira Língua (L1) - como os surdos - e pelos ouvintes que têm, na Língua Portuguesa, a sua L1, simultaneamente, é um desafio, pois esses sistemas linguísticos são produzidos e processados de maneira diferenciada: ao passo que a Libras é uma língua de natureza visual/gestual, a Língua Portuguesa é oral/auditiva. Dessa forma, as estratégias utilizadas pelo professor, nas situações de aprendizagem precisam ser cuidadosamente pensadas, de maneira a contemplar as múltiplas formas de interação do estudante com os colegas e com o conhecimento.

De acordo com o Decreto 5.626, no Art. 2o, o surdo é a pessoa que “[...] por ter perda auditiva, compreende e interage com o mundo por meio de experiências visuais, manifestando sua cultura principalmente pelo uso da Língua Brasileira de Sinais - Libras" (BRASIL, 2005, grifo nosso). Nessa perspectiva, o uso de recursos e estratégias pautadas na multimodalidade podem se constituir em uma alternativa que precisa ser apresentada aos licenciandos e as impressões sobre essa experiência, discutida junto aos alunos do curso de Pedagogia, por estarem em processo de formação para ensinar crianças (surdas ou ouvintes) nas etapas iniciais do processo de aquisição da linguagem. 
A multimodalidade, para Descardeci (2002), compreende comunicações compostas por mais de um modo de representação e pode envolver aspectos inerentes à língua, tais como a forma de expressão oral/escrita e outros recursos utilizados para compor a mensagem que também contribui no processo de atribuição de sentidos pelo interlocutor. Nesse sentido, nenhum sinal ou código deve ser estudado isoladamente, mas no contexto de uso, pois são compostos por elementos verbais e não verbais. Nas palavras da autora, as produções e análises desses textos devem ocorrer "[...] no uso que se pretende fazer delas em situações específicas de formas de interação" (DESCARDECl, 2002, p. 21, grifo da autora).

Nesse seguimento, a investigadora supracitada acrescenta que as representações do mundo realizadas pela criança extrapolam o limite da palavra, pois, antes de se apropriarem do código escrito, elas leem/significam o mundo por meio de "[...] imagens, cores, formatos; ou ainda através de gestos, sabores, cheiros e tatos. O chão, o papel, o tecido, as pessoas, e, mais modernamente, as mídias eletrônicas, como o computador" (DESCARDECl, 2002, p. 20). Diante disso, planejamos uma atividade que objetivava instrumentalizar o licenciando em Pedagogia a utilizar o potencial da multimodalidade para inserir a Libras nas atividades educacionais, em uma perspectiva de aprendizagem significativa.

Rogers (2014, p. 1) afirma que a aprendizagem significativa é aquela que supera uma acumulação de fatos, provoca uma modificação no indivíduo seja no comportamento, na percepção da realidade e expectativas para o futuro, nas suas atitudes e/ou personalidade. Desse modo, buscamos promover uma atividade que tivesse desdobramentos para além da produção linguística e que ensejasse reflexões sobre o uso da Libras em função dos elementos necessários para a sua produção; que evidenciasse as limitações de uso desse sistema comunicativo pelo usuário; e estimulasse a busca por alternativas para a produção de textos em função do objetivo e da situação de uso.

\section{Metodologia}

Tal como Daltro e Faria (2019, p. 223), utilizamos o relato de experiência (RE) como metodologia. Segundo esses autores, o RE é "[...] como produto científico próprio às ciências humanas" e à pósmodernidade que permite uma releitura da realidade, para a análise do fenômeno em uma perspectiva científica. Para compor o relato, seguimos as orientações de Daltro e Faria (2019, p. 230) ao explicar que “o Relato demonstra a história, histórias e a importância de haver vozes plurais para contá-la(s)" e, por esse motivo, compomos um grupo de discussão para a produção do texto com a docente que ministrou a disciplina; uma egressa que na ocasião da situação relatada era aluna da referida turma; e uma 
colaboradora externa, que tem publicações sobre Libras, para que pudéssemos analisar o fenômeno (que as autoras chamam de história) sobre três olhares (que são as histórias).

Para fundamentar o relato, que será analisado em uma perspectiva qualitativa, revisitamos documentos produzidos durante a aplicação da atividade analisada, ou seja, a produção de apresentação de personagens com a turma de Pedagogia (diurno) do CFP/UFCG, no semestre 2016.2, tais como registro de aulas, fotografias, planejamentos e impressões registradas no diário de campo da docente ministrante bem como anotações para a produção do texto que foram elaborados pela licencianda.

Ainda na perspectiva de Daltro e Faria (2019), realizamos uma produção narrativa, que ultrapassa a descrição dos fatos, à medida que busca analisá-los à luz de teorias de ensino de línguas e nas atividades promovidas na licenciatura para uso e ensino bilíngue em classes inclusivas com surdos.

\section{Resultados}

A Universidade onde aconteceu o relato é uma instituição da rede pública federal de ensino, na qual os cursos oferecidos no Campus estão voltados para a formação de professores e profissionais da saúde. Sua localidade geográfica favorece o acesso de alunos de três estados do Nordeste brasileiro, possibilitando o atendimento de um número significativo de alunos oriundos, principalmente, de cidades dos estados do Ceará, do Rio Grande do Norte e da Paraíba.

No curso de Pedagogia dessa instituição, duas disciplinas, ambas ofertadas com carga horária de 60h/a tratam, especificamente, de conteúdos que se relacionam com a educação inclusiva, são elas: Educação Inclusiva e Libras. A ementa da disciplina de Libras delimita que esse componente curricular é proposto na perspectiva de "Promover o estudo da Língua de Sinais e da educação para pessoas surdas nas suas dimensões básicas: o saber, o fazer e o ser. Analisar a educação inclusiva como espaço interdisciplinar a partir das práticas sociais sobre diversidade e identidade" (UNIVERSIDADE FEDERAL DE CAMPINA GRANDE, 2009, p. 49, grifo nosso), logo, a indissociabilidade do uso da Libras e das práticas educacionais utilizando essa língua são destacadas, influenciando na formação do docente.

Notamos, assim, na ementa, uma intrínseca relação entre os componentes curriculares anteriormente citados tendo em vista que o Projeto Pedagógico do Curso (PPP) compreende as práticas educativas para surdos como uma das dimensões que compõem a educação inclusiva e assegura a interdisciplinaridade dos conhecimentos abordados nesses dois componentes. Desse modo, a atividade desenvolvida nesse relato pode ser percebida, a partir do PPP, como interdisciplinar, porque envolve 
conhecimentos que tratam não só da Libras, como do seu uso em uma perspectiva inclusiva.

\section{Produção de apresentação de personagem infantil em uma perspectiva lúdica e inclusiva}

Para compreender a atividade, destacamos que o texto é conceituado como um conjunto de linguagens utilizadas para sua composição, ou seja, em uma perspectiva multissemiótica, conforme apresenta Descardeci (2002), portanto, extrapola os sinais e envolve aspectos não verbais característicos do contexto de produção da mensagem. Assim, dividimos o relato em três etapas (proposta da atividade, planejamento e apresentação) de maneira a discutir os ajustes realizados entre a idealização dessa atividade e a apresentação dos resultados.

\section{Proposta da atividade}

No primeiro momento, a docente de Libras explicou a proposta de produção de uma apresentação/descrição de um personagem, em Libras, como atividade de avaliação. Em seguida explicou as características do texto descritivo, utilizando o material de Oliveira e Castro (2008) e, na sequência realizou uma demonstração de apresentação de uma personagem em Libras, com sentenças nas quais predominava o uso de pronomes, verbos e adjetivos. A estrutura do texto sinalizado pela docente privilegiava a utilização de sentenças curtas na composição de modo a favorecer a compreensão de estudantes em estágio inicial de aprendizado da Libras.

Nessa oportunidade, foi acordado com o grupo que as informações sobre o personagem (tais como características físicas, preferências, ambiente no qual se passa a história que fazem parte, entre outros) deveriam compor a primeira parte do texto, e a datilologia e o sinal do personagem seriam revelados, apenas, ao final. A datilologia que é um código de representação de letras do alfabeto por configurações da mão, formas da mão usadas para produzir sinais (ALBRES, 2014).

Para subsidiar a escolha do personagem, a docente da IES disponibilizou três links de vídeos que estão disponíveis gratuitamente em um site de compartilhamento de vídeos, o YouTube.com, sendo eles: Super-Herói (Libras) ${ }^{5}$, Sinalário - Personagens de História Infantil ${ }^{6}$ e Curso de Libras: Super herói ${ }^{7}$. A partir

\footnotetext{
${ }^{5}$ Disponível em: https://www.youtube.com/watch?v=716DLaktkQY

${ }^{6}$ Disponível em: https://www.youtube.com/watch?v=V0CgjgqDRFw

${ }^{7}$ Disponível em: https://www.youtube.com/watch?v=prSRU-B6Peg
} 
desses vídeos ou de outras fontes de pesquisa de sinais (como glossários e dicionários impressos e disponibilizados online), os licenciandos poderiam selecionar um dos personagens, contudo, ao fazer a escolha, deveriam informá-la aos demais colegas no grupo da turma criado por meio do aplicativo WhatsApp, de maneira que cada licenciando apresentasse um personagem diferente. Primeiramente, porque a atividade estava voltada para discutir a possibilidade de ser replicada para o público infantil, que poderia ser composto por crianças que não tivessem se apropriado do sistema de escrita em Língua Portuguesa; e, em segundo lugar, por ser uma atividade de valorização da Libras como uma língua que deve ser utilizada por estudantes e professores na escola, por isso, a datilologia deveria ser evitada.

Além do texto, os licenciandos deveriam utilizar um objeto ou vestimenta que fizesse menção ao personagem a ser descrito de forma que funcionasse como uma pista visual para auxiliar na compreensão do texto sinalizado e a revelar a identidade do personagem. Assim, com o uso dessa pista, a apresentação objetivava incorporar elementos contextuais para a ativação dos conhecimentos prévios dos estudantes, de maneira a favorecer a significação da mensagem expressa em Libras.

\section{Etapa preparatória}

Delimitado o personagem e conhecendo a estrutura do texto, os licenciandos iniciaram a produção sinalizada. Para isso, foram disponibilizados momentos, ao fim das aulas, para que os discentes realizassem o planejamento do texto e tivessem o suporte da docente da IES e da monitora na versão das informações para a Libras. Esse atendimento se estendeu, de maneira remota, via WhatsApp.

Nessa etapa, observamos que a maioria dos licenciandos optou por produzir a escrita na Língua Portuguesa e, posteriormente, buscar nos dicionários e glossários virtuais os sinais equivalentes para realizar a tradução do texto. Nesse processo, os licenciandos perceberam uma variedade de vocábulos em Libras utilizados para representar um mesmo conceito. Esses significantes se dividiam em dois grupos: unidades lexicais que correspondiam à mesma palavra em Língua Portuguesa, mas que os sinais eram utilizados em contextos específicos em Libras; e as variações regionais, que correspondem às mudanças na produção de um sinal observado em sinalizantes de diferentes idades e/ou regiões geográficas (ALBRES, 2014). Esta última proporcionou maior discussão, já que os materiais de apoio sugeridos foram produzidos por sinalizantes do Sul do País, a exemplo dos dicionários de Libras disponibilizado em no site Acessibilidade Brasil (figura 1) e o impresso (figura 2). 
Figura 1

Dicionário de Libras online

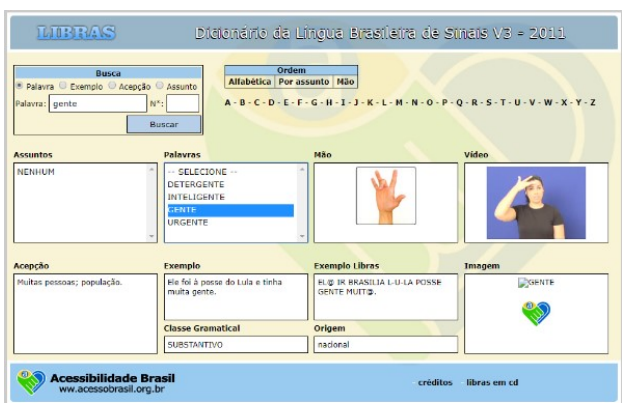

Fonte: Acessibilidade Brasil (2011).
Figura 2

Dicionário de Libras impresso

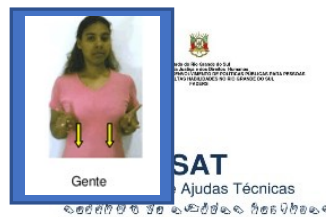

Mini dicionário

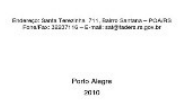

Fonte: Cláudio et al. (2010).

O sinal em destaque, em ambos os dicionários (online e impresso), se refere ao conceito de "gente", entretanto, ao observarmos a sua produção nas figuras 1 e 2, identificamos que o significante (que é a forma do sinal) é diferenciado em cada dicionário. Essas variações, inicialmente, causaram inquietações nos estudantes que, frequentemente, perguntavam sobre qual sinal era o "correto".

Essa oportunidade foi considerada produtiva porque os licenciandos puderam, de maneira ativa e significativa, identificar os materiais gratuitos de divulgação do vocabulário em Libras disponíveis na internet utilizando o computador pessoal ou o celular, analisar as diferenças entre a organização gramatical da Língua Portuguesa e da Libras durante a tradução do texto e identificar os diversos usos de que um sinal em Libras pode assumir a depender dos contextos.

Para os licenciandos que atuarão na região destacada, que apresenta proximidade de outros estados brasileiros, a compreensão da variação linguística é essencial, porque eles podem se deparar com sinalizantes que receberam influências linguísticas de usuários da Libras de estados limítrofes da região onde moram. Assim, na oportunidade, foram exemplificadas situações nas quais esse fenômeno ocorre na Língua Portuguesa, a exemplo da palavra macaxeira, conhecida como mandioca no Sul do País, ou a mexerica, conhecida como tangerina, em outras regiões do País. Com isso, os discentes compreenderam que a variação é uma característica das línguas, ou seja, não se restringe só à produção em Libras.

Em situações nas quais os licenciandos não encontraram o sinal em Libras correspondente ao referente em Língua Portuguesa, notamos a opção pela reformulação ou omissão da sentença para 
evitar o uso de datilologia, conforme solicitado pela docente. Os discentes relataram que, nessa etapa, além de recorrerem a dicionários impresso, online, suporte da docente e da monitoria da disciplina, eles analisaram vídeos disponíveis no YouTube e auxílio de usuários mais fluentes em Libras como professores e Tradutores Intérpretes da Libras que moravam próximo às suas residências.

Elaborado o texto em Libras, os licenciandos iniciaram a construção da tradução da Língua Portuguesa para a Libras. Esses registros assemelham-se às glosas, um sistema de registro de apoio à tradução. Para isso, uma palavra em português é usada para relembrar o referido sinal em Libras e esse vocábulo pode ser associado às descrições que objetivam ativar a memória do enunciador. Nesse processo é possível utilizar-se de letras, números ou imagens - o que os autores chamam de códigos sobrescritos - de maneira a compor um registro que possibilite ao sinalizante lembrar das sequências a serem sinalizadas (MCCLEARY; VIOTTI; LEITE, 2010). A produção desses registros, elaborados com características de multimodalidade, não seguiu nenhuma orientação linguística dada pela docente, elas foram incentivadas apenas para servir como suporte à memorização para a execução do sinal.

Os licenciandos optaram por realizar, antecipadamente, o treino da sinalização com colegas no espaço da aula destinado para a elaboração da atividade (geralmente, ao fim das aulas). Consideramos que essa etapa gerou aprendizados sobre a língua em diferentes níveis, tais como lexical (busca por sinais), gramatical (elaboração do texto em Libras), semântico (seleção do sinal mais adequado para expressar o significado) e pragmático (seleção do sinal e outras estratégias linguísticas adequadas para expressar o texto em função do público).

\section{Apresentação do texto}

Para a apresentação dos textos foram disponibilizadas 2 h/a. Notamos que prevaleceram dois critérios para a escolha do personagem: facilidade de conseguir o empréstimo de uma fantasia e as condições de produção de figurino. Os licenciandos que se enquadram no segundo caso, percebemos a identificação mais próxima entre as características do personagem e do discente, revelando suas preferências. Nas figuras 3 e 4 podemos identificar a representação não verbal de duas personagens ${ }^{8}$.

\footnotetext{
${ }^{8}$ A utilização das imagens foi devidamente autorizada pelas fotografadas conforme Termo de Autorização do Uso de Imagem.
} 


\section{Figura 3}

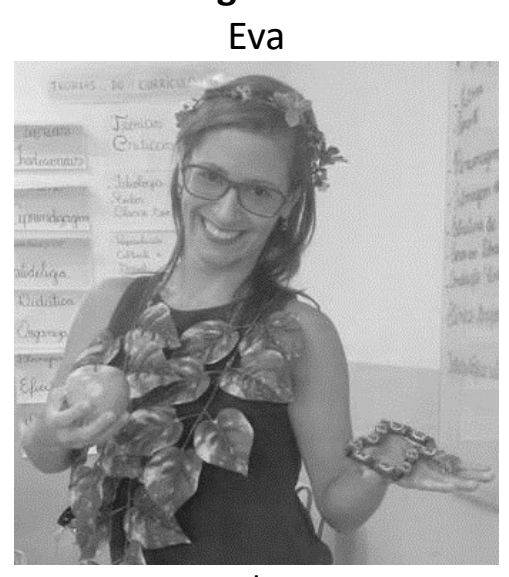

Fonte: Acervo das autoras.
Figura 4

Mulher Maravilha

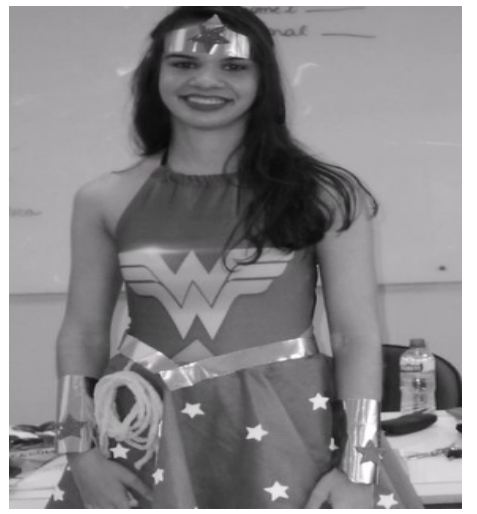

Fonte: Acervo das autoras.

Percebemos que a opção pelo uso de figurino pelas sinalizantes ofereceram pistas para a compreensão dos sinais, porque contribuíram no resgate dos conhecimentos prévios dos interlocutores sobre a temática abordada. Dentre os personagens apresentados pelos licenciandos, evidenciamos as super-heroínas as quais citamos a Mulher Maravilha, Mulher Hulk, Mulher Gato e Mulher Gavião; Personagens de contos de fadas, como: Sininho, Branca de Neve, Rapunzel, Cinderela, Espantalho, Porquinhas e a Loba Má, Papai Noel, Bela e a Fera, Bruxa, Narizinho, Cuca, Alice, Pequeno Polegar e Chapeuzinho Vermelho; Personagens de Histórias em Quadrinhos, a exemplo da Mônica, da Minnie, do Chico Bento e da Rosinha; Personagens da TV, como a Chiquinha, o Chaves, a Vilma Flintstone, a Barbie, o Naruto e a She-Ra; além da Bailarina e da Fada.

No momento da apresentação, a docente de Libras auxiliou os licenciandos a relembrarem a execução de sinais que foram esquecidos e ofereceu suporte ao indicar os ajustes necessários para a produção adequada do sinal, em especial, daqueles sinais em que a mudança produzida pelos discentes que geravam alteração no significado da informação. Além disso, quando as produções de texto foram consideradas curtas, a referida docente realizou questionamentos, em Libras, de modo que estimulassem os licenciandos a apresentarem outras características sobre o personagem que não foram abordadas. Essas intervenções foram discutidas com o grupo e analisadas sob a orientação de autores como Tardif (2014) que descreve os saberes necessários para a formação docente, entre eles os saberes pessoais (construídos na experiência) e profissionais (forjados na formação para a docência).

A atividade contribuiu ainda para que os discentes percebessem a relevância dos fatores 
extralinguísticos na produção do seu próprio texto e dos colegas. Os fatores extralinguísticos que nos referimos são aqueles que se relacionam ao sistema linguístico, mas sem pertencer a ele, entretanto, são elementos que contribuem para a transmissão da mensagem e englobam expressões do corpo, variações na velocidade, tons da voz etc. (DICIONÁRIO MICHAELIS, 2020).

Logo, na Libras, eles se expressam em detalhes da produção em Libras como a diferença da sinalização (velocidade, expressão corporal, facial, etc.) realizada pelo licenciando, para revelar características do personagem, ou seja, quando se tratava de uma princesa, a sinalização era realizada de maneira mais delicada, já para uma heroína, a sinalização era mais marcada. Além disso, as expressões facial e corporal completavam a composição desses elementos, pois, durante a apresentação dos textos nos quais a personagem era uma princesa, notamos que a sinalizante produzia o texto com pés juntos; quando se tratava de heroínas os pés eram dispostos separados; e, para as crianças, as sinalizantes curvavam, sutilmente, os pés para dentro. Essa expressão corporal não havia sido discutida nas aulas, mas foram elaboradas pelos discentes a partir do contato com outros textos trabalhados em classe e buscados na internet, bem como mediante as suas próprias impressões sobre a sinalização.

A experiência trouxe como pontos positivos o incentivo à produção autoral dos licenciandos, o aprendizado sobre a língua, não só na identificação dos recursos disponíveis para ampliação de vocábulos, como também a vivência de construção de textos em Libras em função de um gênero. Todavia, entendemos que apesar do estímulo à composição autoral, a atividade privilegiou o momento da enunciação em detrimento do diálogo. Diante disso, é necessário como estratégia de aplicação futura da atividade inserir, no planejamento, uma proposta que estimule os demais colegas a realizarem questionamentos, afirmações ou negações aos discentes que apresentem os personagens, tornando, desse modo, a atividade mais interativa.

\section{Considerações finais}

A discussão em tela tratou de uma atividade desenvolvida para o ensino de Libras na Universidade, que teve como objetivo associar diferentes habilidades comunicativas requeridas ao licenciando que irá atuar em classes inclusivas com surdos, as quais destacamos: o uso da Língua e o estímulo à inserção dessa língua como sistema de comunicação de instrução.

Concluímos que a atividade promoveu a participação ativa dos discentes e, assim, aprendizados 
múltiplos no âmbito da pesquisa, como a busca de fontes que permitissem a composição do texto; a ampliação dos conhecimentos sobre a Libras, em diferentes níveis, como lexical, gramatical, semântico e pragmático; a composição do texto descritivo; a seleção dos elementos multimodais que incidem no registro (como as glosas) e na apresentação da produção, a exemplo da expressão facial, corporal, da velocidade da sinalização e das pistas visuais que compõem a enunciação.

Nesse sentido, a atividade proporcionou reflexões sobre a Língua Portuguesa, sobre a Libras, sobre os elementos que interferem na composição do texto, como objetivo, contexto, público, bem como no planejamento e uso de atividades produzidas na perspectiva de divulgar e promover o uso da Libras em classes e em escolas inclusivas com surdos. Consideramos ainda que essa atividade pode ser replicada com estudantes da Educação Básica, de modo a incentivar, de maneira lúdica, o interesse pelo aprendizado da Libras, possibilitando aos estudantes ouvintes a interagirem em Libras - entre si e com os colegas surdos - de forma a favorecer a participação do surdo em diferentes contextos sociais.

Acreditamos que a composição do relato possibilitou revisitar as práticas realizadas nessa turma e analisar os aspectos favoráveis, antecipar aquelas que não foram previstas, otimizar a proposta em oportunidades de modo a ampliar o aprendizado dos licenciandos.

\section{Referências}

ACESSIBILIDADE BRASIL. Dicionário da Língua Brasileira de Sinais. v. 3. 2011. Disponível em: http://www.acessibilidadebrasil.org.br/libras_3/ Acesso em: 17 abr. 2020.

ALBRES, Neiva de Aquino. Estudo léxico da Libras: uma história a ser registrada. In: LACERDA, Cristina Broglia Feitosa de; SANTOS, Lara Ferreira dos. Tenho um aluno surdo, e agora? Introdução à Libras e à educação dos surdos. Edufscar: São Carlos, 2014.

BRASIL. Lei no 9.394, 20 de dezembro de 1996. Estabelece as diretrizes e bases da educação nacional. Disponível em: http://portal.mec.gov.br/seed/arquivos/pdf/tvescola/leis/lein 9394.pdf. Acesso em: 17 abr. 2020.

BRASIL. Decreto no 5.626, de 22 de dezembro de 2005. Regulamenta a Lei no 10.436, de 24 de abril de 2002, que dispõe sobre a Língua Brasileira de Sinais - Libras, e o art. 18 da Lei no 10.098, de 19 de dezembro de 2000. Disponível em: http://www.planalto.gov.br/ccivil 03/ Ato20042006/2005/Decreto/D5626.htm. Acesso em: 17 abr. 2020.

BRASIL. Lei no 12.319, de 1 de setembro de 2010. Regulamenta a profissão de Tradutor e Intérprete da Língua Brasileira de Sinais - LIBRAS. Disponível em: https://presrepublica.jusbrasil.com.br/legislacao/1025011/lei-12319-10. Acesso em: 17 abr. 2020. 
CLÁUDIO, Janaína Pereira et al. Mini Dicionário. Porto Alegre: CAS/FADERS, 2010.

DALTRO, Mônica Ramos; FARIA, Anna Amélia de. Relato de experiência: uma narrativa científica na pósmodernidade. Estudos e Pesquisas em Psicologia, Rio de Janeiro, v. 19, n. 1, p. 223-237, jan./abr. 2019. Disponível em: https://www.e-publicacoes.uerj.br/index.php/revispsi/article/view/43015. Acesso em: 25 mar. 2020.

DESCARDECI, Maria Alice Andrade de Souza. Ler o mundo: um olhar através da semiótica social. Educação Temática Digital, Campinas, v. 3, n. 2, p. 19-26, jun., 2002. Disponível em: https://periodicos.sbu.unicamp.br/ojs/index.php/etd/article/view/604. Acesso em: 17 abr. 2020.

EXTRALINGUÍSTICO. In: Michaelis Dicionário Brasileiro de Língua Portuguesa. Editora Melhoramentos, 2020. Disponível em: http://michaelis.uol.com.br/busca?id=db74. Acesso em: 17 abr. 2020.

MCCLEARY, Leland Emerson; VIOTTI, Evani de Carvalho; LEITE, Tarcísio de Arantes. Descrição de línguas sinalizadas: a questão da transcrição dos dados. Alfa: Revista de Linguística, São José do Rio Preto, v. 54, n. 1, p. 265-289, 2010. Disponível em: https://periodicos.fclar.unesp.br/alfa/article/view/2880/2654. Acesso em: 17 abr. 2020.

OLIVEIRA, João Batista Araújo; CASTRO, Juliana Cabral Junqueira. Usando textos na sala de aula: tipos e gêneros textuais. 3. ed. Brasília: Instituto Alfa e Beto, 2008.

ROGERS, Carl Ransom. Tornar-se pessoa. 8. ed. São Paulo: Martins Fontes, 2014.

TARDIF, Maurice. Saberes docentes e formação profissional. 17. ed. Petrópolis: Ed. Vozes, 2014.

UNIVERSIDADE FEDERAL DE CAMPINA GRANDE. Projeto Pedagógico do Curso de Pedagogia. Cajazeiras: UFCG, 2009. 